Molecular Structure Corporation (1993a). R-Axis Processing Software. MSC, 3200 Research Forest Drive, The Woodlands, TX 77381, USA.

Molecular Structure Corporation (1993b). AFC-7R Processing Software. MSC, 3200 Research Forest Drive, The Woodlands, TX 77381 , USA.

Norrestam, R. (1984). Acta Cryst. C40, 297-299.

Thailambal, V. G., Pattabhi, V. \& Guru Row, T. N. (1986). Acta Cryst. C42, 587-589.

Watkin, D. J., Prout, C. K., Carruthers, R. J. \& Betteridge, P. (1996). CRYSTALS. Issue 10. Chemical Crystallography Laboratory, University of Oxford, England.

Watkin, D. J., Prout, C. K. \& Pearce, L. J. (1996). CAMERON. Chemical Crystallography Laboratory, University of Oxford, England.

Acta Cryst. (1998). C54, 1191-1192

\section{myo-Inositol 1,3,5-Bicyclic Phosphate}

\section{Stephen Neidle, ${ }^{a}$ Piers R. J. Gaffney ${ }^{b}$ and Colin B. $\operatorname{REESE}^{b}$}

${ }^{a}$ CRC Biomolecular Structure Unit, The Institute of Cancer Research, Cotswold Road, Sutton, Surrey SM2 5NG, England, and ${ }^{b}$ Department of Chemistry, King's College London, Strand, London WC2R 2LS, England. E-mail: steve@iris5.icr.ac.uk

(Received 18 December 1996; accepted 21 November 1997)

\section{Abstract}

In the crystal structure of the title compound (4,6,10-trihydroxy-2,8,9-trioxa-1-phosphatricyclo[3.3.1.1 $\left.{ }^{3,7}\right]$ decane $P$-oxide, $\left.\mathrm{C}_{6} \mathrm{H}_{9} \mathrm{O}_{7} \mathrm{P}\right)$, the cyclohexane ring is in a chair conformation. Two hydroxy substituents are in axial orientations and the third is equatorial. There is an intramolecular hydrogen bond involving the two axial hydroxy groups.

\section{Comment}

A number of phosphate esters of D-myo-inositol are of considerable importance inasmuch as they display profound biological activity in the cell as second messengers (Berridge, 1987). Our studies directed towards the synthesis of these phosphate esters (Gaffney \& Reese, 1997) led us to the preparation of the title compound, (1), which has an adamantane-like structure of particular interest. The preparation of compound (1) has also been reported by Chinese workers (Yuan \& Zhai, 1992). This is the first reported crystal structure of a cyclic phosphate of inositol; the structures of three other non-cyclic phosphates are available in the literature (Spiers et al., 1995).

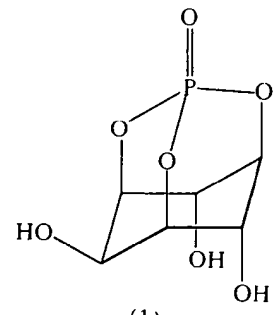

(1)

The cyclohexane ring adopts the expected chair conformation, with the 2-, 4- and 6-hydroxy substituents being axial, equatorial and axial, respectively. There is an intramolecular hydrogen bond between the $\mathrm{O} 6$ atom as donor and $\mathrm{O} 5$ as acceptor (Table 2). All three hydroxy groups, as well as the phosphate oxygen atom $\mathrm{Ol}$, participate in intermolecular hydrogen bonding in the crystal lattice. Atom $\mathrm{O} 5$ participates in an asymmetric bifurcated hydrogen bond with acceptors $\mathrm{O6}$ and $\mathrm{O} 7$. The $\mathrm{H}$ atom donated from $\mathrm{O} 5$ is evidently closer to $\mathrm{O} 7$, as judged by the angles involved.

The bicyclic phosphate/cyclohexane moiety has approximate threefold symmetry. The three $\mathrm{P}-\mathrm{O}$ single bonds, of average length $1.580 \AA$, are all equivalent within significant error, as are the $\mathrm{O}-\mathrm{P}-\mathrm{O}$ bond angles (average $104.5^{\circ}$ ). The $\mathrm{P}-\mathrm{O} 1$ bond is of pure doublebond character (Allen et al., 1987).

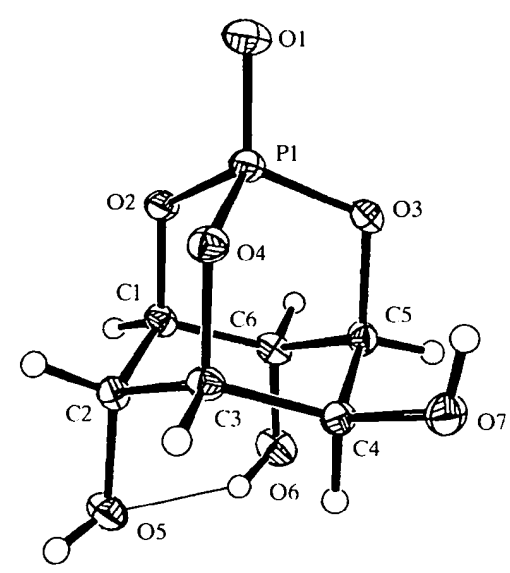

Fig. 1. View of the title structure. Displacement ellipsoids are shown at the $50 \%$ probability level. $\mathrm{H}$ atoms have been drawn as small circles of arbitrary radii.

\section{Experimental}

The title compound was crystallized by slow evaporation from a methano/2-propanol solution.

\section{Crystal data}
$\mathrm{C}_{6} \mathrm{H}_{9} \mathrm{O}_{7} \mathrm{P}$
$M_{r}=224.10$

$$
\begin{aligned}
& \text { Mo } K \alpha \text { radiation } \\
& \lambda=0.7107 \AA
\end{aligned}
$$

Acta Crystallographica Section C ISSN 0108-2701 @ 1998 
Monoclinic

$P 2_{1} / c$

$a=9.2892(6) \AA$

$b=9.0724(5) \AA$

$c=9.5328(12) \AA$

$\beta=96.150(6)^{\circ}$

$V=798.76(12) \AA^{3}$

$Z=4$

$D_{x}=1.864 \mathrm{Mg} \mathrm{m}^{-3}$

$D_{m}$ not measured

\section{Data collection}

Enraf-Nonius FAST areadetector diffractometer

$\omega$ scans

Absorption correction: none

3136 measured reflections

1194 independent reflections

\section{Refinement}

Refinement on $F^{2}$

$R\left[F^{2}>2 \sigma\left(F^{2}\right)\right]=0.039$

$w R\left(F^{2}\right)=0.098$

$S=0.576$

1194 reflections

163 parameters

$\mathrm{H}$ atoms freely refined with $U_{\text {iso }}$
Cell parameters from 250 reflections

$\theta=2-22^{\circ}$

$\mu=0.357 \mathrm{~mm}^{-1}$

$T=293$ (2) K

Square plate

$0.30 \times 0.20 \times 0.07 \mathrm{~mm}$

Colourless

989 reflections with

$I>2 \sigma(I)$

$R_{\text {int }}=0.081$

$\theta_{\max }=24.88^{\circ}$

$h=-10 \rightarrow 9$

$k=-10 \rightarrow 10$

$l=-10 \rightarrow 10$

$w=1 /\left[\sigma^{2}\left(F_{o}^{2}\right)+(0.1222 P)^{2}\right.$ $+0.4645 P]$

where $P=\left(F_{o}^{2}+2 F_{c}^{2}\right) / 3$

$(\Delta / \sigma)_{\max }<0.001$

$\Delta \rho_{\max }=0.308 \mathrm{e}^{-3}$

$\Delta \rho_{\min }=-0.493{\mathrm{e} \AA^{-3}}^{-3}$

Extinction correction: none

Scattering factors from

International Tables for

Crystallography (Vol. C)

Table 1. Selected geometric parameters $\left(\AA^{\circ}{ }^{\circ}\right)$

$\begin{array}{llll}\mathrm{Pl}-\mathrm{O} 1 & 1.448(2) & \mathrm{Pl}-\mathrm{O} 3 & 1.581(2) \\ \mathrm{Pl}-\mathrm{O} 4 & 1.574(2) & \mathrm{Pl}-\mathrm{O} 2 & 1.584(2) \\ \mathrm{O} 1-\mathrm{Pl}-\mathrm{O} 4 & 113.74(9) & \mathrm{O}-\mathrm{Pl}-\mathrm{O} 2 & 113.28(9) \\ \mathrm{O} 1-\mathrm{Pl}-\mathrm{O} 3 & 115.09(9) & \mathrm{O} 4-\mathrm{Pl}-\mathrm{O} 2 & 104.45(9) \\ \mathrm{O} 4-\mathrm{Pl}-\mathrm{O} 3 & 104.68(8) & \mathrm{O} 3-\mathrm{Pl}-\mathrm{O} 2 & 104.50(8)\end{array}$

Table 2. Hydrogen-bonding geometry $\left(\AA,^{\circ}\right)$

\begin{tabular}{|c|c|c|c|}
\hline$D-\mathrm{H} \cdots A$ & H. A & $D \cdots A$ & $D-\mathrm{H} \cdots A$ \\
\hline $\mathrm{O} 6-\mathrm{HO} 6 \mathrm{O} 5$ & $2.07(2)$ & $2.779(3)$ & $148.3(12)$ \\
\hline $\mathrm{O} 5-\mathrm{HO}=\cdots \mathrm{O}^{\mathrm{i}}$ & $2.70(3)$ & $2.909(3)$ & $97.3(13)$ \\
\hline $\mathrm{O} 5-\mathrm{HO} \cdots \mathrm{O}^{\mathrm{i1}}$ & $2.02(3)$ & 2.797 (3) & $167.5(13)$ \\
\hline $\mathrm{O} 7-\mathrm{HO} \cdots \mathrm{Ol}^{\mathrm{in}}$ & $2.07(3)$ & $2.760(3)$ & $162.5(14)$ \\
\hline
\end{tabular}

Symmetry codes: (i) $1-x,-y,-z ;$ (ii) $x,-\frac{1}{2}-y,-\frac{1}{2}+z$; (iii) $-x,-y, 1-z$.

Data collection: MADNES (Pflugrath \& Messerschmidt, 1990). Cell refinement: MADNES. Data reduction: MADNES. Program(s) used to solve structure: SHELXS86 (Sheldrick, 1990). Program(s) used to refine structure: SHELXL93 (Sheldrick, 1993). Molecular graphics: ORTEX (McArdle, 1993). Software used to prepare material for publication: SHELXL93.

We are grateful to the Cancer Research Campaign for a grant (to SN) in support of this work. X-ray data were collected at the EPSRC Crystallographic Service, University of Wales, Cardiff, Wales. Professor M. B. Hursthouse is thanked for providing access to this facility.

Supplementary data for this paper are available from the $\mathrm{IUCr}$ electronic archives (Reference: CF1164). Services for accessing these data are described at the back of the journal.

\section{References}

Allen, F. H., Kennard, O., Watson, D. G., Brammer, L., Orpen, A. G. \& Taylor, R. (1987). J. Chem. Soc. Perkin Trans. 2, pp. S1-S19.

Berridge, M. J. (1987). Ann. Rev. Biochem. 56, 159-193.

Gaffney, P. R. J. \& Reese, C. B. (1997). Unpublished results.

McArdle, P. (1993). J. Appl. Crist. 26, 752.

Pflugrath, J. W. \& Messerschmidt, A. (1990). MADNES. Munich AreaDetector Systems. Enraf-Nonius, Delft, The Netherlands.

Sheldrick, G. M. (1990). Acta Cryst. A46, 467-473.

Sheldrick, G. M. (1993). SHELXL93. Program for the Refinement of Crystal Structures. University of Göttingen, Germany.

Spiers, I. D., Freeman, S. \& Schwalbe, C. H. (1995). J. Chem. Soc. Chem. Commun. pp. 2219-2220.

Yuan, C. \& Zhai, H. (1992). Phosphorus Sulfur Silicon, 69, 71-74. 